\title{
Effects of Fairness and Relationship Quality on Relational Behavior
}

\author{
Zafer Kamil Berkman \\ Department of Management, Boğaziçi University, İstanbul, Turkey \\ Email: zaferberkman@yahoo.com
}

How to cite this paper: Berkman, Z. K. (2020). Effects of Fairness and Relationship Quality on Relational Behavior. American Journal of Industrial and Business Management, 10, 1163-1180. https://doi.org/10.4236/ajibm.2020.107079

Received: June 23, 2020

Accepted: July 12, 2020

Published: July 15, 2020

Copyright $\odot 2020$ by author(s) and Scientific Research Publishing Inc. This work is licensed under the Creative Commons Attribution International License (CC BY 4.0).

http://creativecommons.org/licenses/by/4.0/

(c) (i) Open Access

\begin{abstract}
To be an effective global competitor requires to be a trusted cooperator in some network. This argument defines the essence of marketing channel partnerships. Relational behaviors have a conclusive effect in the success of marketing initiatives; hence, they are amongst the variables that set apart a good partnership. How do fairness and relationship quality affect relational behaviors? This study aims to answer these questions for a channel setting that comprises the marketing firm and the retailers. Research data were gathered from four hundred Tekel shops, Turkish tobacco and liquor convenience shops by using face to face interviewing technique. Prior research mostly studied the effects of fairness on relational behaviors and on relationship quality dimensions. This study aims to explore the mediating role of relationship quality. Scales were developed from the existing literature, adopted for the research context, and tested for reliability and validity. Structural equation modeling was used to test the research data. The study establishes the mediating role of the relationship quality for the effect of fairness on relational behaviors.
\end{abstract}

\section{Keywords}

Fairness, Relationship Quality, Relational Behaviors, Marketing Channels, Relationship Marketing, Relational Exchange, Relational Contracts

\section{Introduction}

Marketing firms vastly rely on their trade distribution partners to reach retailers and consumers. Firms consider partnering with distributors mainly for economic reasons and increased efficiency in carrying out initiatives (Thorelli, 1986; Dyer \& Singh, 1998; Achrol \& Kotler, 1999; Geyskens, Steenkamp, \& Kumar, 2006). Therefore, they invest in structural control measures to ensure the conti- 
nuum of their marketing process across the boundaries of partner organizations. Developing and proctoring binding legal contracts is one of these activities (Lusch \& Brown, 1996; Antia \& Frazier, 2001). However, socially rich and long term nature of trade relationships (Frazier \& Summers, 1984; Skinner, Gassenheimer, \& Kelley, 1992; Wilkinson, 1979; Heide, Wathne, \& Rokkan, 2007) and the need for creative daily decision making, necessitate the relational norms (Palmatier, Dant, \& Grewal, 2007; Ritter \& Gemünden, 2003; Ivens \& Blois, 2004) and the perspective of social exchange (Homan, 1958; Macneil, 1985; Ring \& Van de Ven, 1994; Griffith, Harvey, \& Lusch, 2005) as facilitators, rather than the enforcement of ever looming threat of legal sanctions of a contract. Regulated environments in terms of marketing and communications activities only add to the importance of relational behaviors. Namely, solidarity, flexibility and information sharing are the established norms for long term trade relationships (Heide \& John, 1992), out of original norms from MacNeil's relational contracting theory (Macneil, 1980).

Cultivating a culture of growing together is at the helm of marketing firms' efforts to obtain relational behaviors (Dyer, Singh, \& Kale, 2008). To grow together, a channel member must trust and commit to the other one and invest in their shared interest (Geyskens, Steenkamp, \& Kumar, 1998). There is also a constant need to manage destructive conflict in order for partners not to exit the relationship or not to restrain themselves behind emotional and manifested barriers (Reve \& Stern, 1979; Gaski, 1984). Early years of channel research is dominated by a focus on power: the examination of the use of different types of power in trade channels and their consequences on conflict and satisfaction (Rosenberg \& Stern, 1970; Hunt \& Nevin, 1974; Lusch, 1976; Wilkinson, 1979; Raven, 2008; Hopkinson \& Blois, 2014; Hunt, 2015). Although effective in explaining how coercive use of power creates destructive conflicts, and in displaying how servant power improves satisfaction (Hunt \& Nevin, 1974); the power literature comes short in attaching itself solidly to relational behaviors. In this direction, Young and Wilkinson (1989) argue that marketing's emphasis on power and conflict as key concepts for studying channels has "distorted the understanding of channels functioned. The emphasis was on sick rather than healthy relationships" (p. 109).

An alternative theory for better-performance, relationship marketing is developed around the idea of competitive advantage created through good management of business relations. Relationship marketing is establishing, developing, and maintaining successful relational exchanges. Morgan and Hunt's (1994) commitment-trust theory of relationship marketing underlines the importance of effective cooperation for business performance and defines trust and commitment as mediating variables for such a cooperation. In parallel, Kumar, Scheer, and Steenkamp (1995) introduced a multidimensional construct, relationship quality (RQ), as central to relationship marketing. Their study shows the effects of fairness on relationship quality, the latter being a construct that envelops conflict, trust, commitment, and willingness to invest and expectation of continuity 
variables. Another line of literature that contributes to understanding of long-term trade relationships is justice, or fairness as it is called in business relationships. Fairness is an antecedent for dimensions of relationship quality and relational behaviors (Dwyer, Schurr, \& Oh, 1987; Ganesan, 1994; Robicheaux \& Coleman, 1994; Weitz \& Jap, 1995; Cohen-Charash \& Spector, 2001; Rauyruen, Miller, \& Barrett, 2007).

Previous relational behavior literature mainly focuses on the relation between the firm and its reseller where the latter is a big franchise outlet as in automotive or in food \& beverage sectors. The aim of this study is to better understand the antecedents of the relational behaviors for a FMCG context and independent small retailers in Turkish channel setting. The context of the study involves a trade segment that can be identified as Turkish Tekel Shops. These are rather convenience type shops that rely heavily on the sales of cold beer and other alcoholic beverages, tobacco, soft drinks along with other food and non-food convenience items. The research also entails firms which have major contribution to sales portfolio of these retailers. By the nature of the products they handle, Tekel Shops and most of the supplier firms that came up in the research operate under marketing and sales regulations. The study examines the effects of fairness on relational behaviors and the mediating role of relationship quality between fairness and relational behaviors.

The channels context is dominated by the need to grow together, and is rich in power, conflict, relational behaviors, trust, fairness, long-term orientation and commitment constructs. A theoretically solid framework to explain what drives retailer's relational behaviors has to benefit from all related literatures. Hence, related literatures and theories were visited and a fairness model that incited relationship quality and relational behaviors is proposed to inquire into research questions. The rest of this work is organized as follows: first, a review of the theoretical background is provided for fairness, relationship quality and relational behavior constructs. The literature review continues with the presentation of the context of research. Next, research methodology is outlined; research model and hypotheses are laid out. Finally, data collection and findings are presented.

\section{Theoretical Background}

\subsection{Relational Behavior and Its Normative Origins}

As Lusch and Brown (1996) states, "Relational governance occurs primarily through a set of relational norms that govern acceptable behavior between channel partners. In a relational governance, implicit or soft contracts identify a set of mutual expectations and understandings between the channel partners, and thus these contracts can be referred as normative contracts" (p. 19). Contracts are normative when a mutual understanding exists between parties as to how they will interact and deal with each other, including the handling of future contingencies. Rousseau (1995) states that "normative contracts reflect a social consensus and 
reinforcement of specific behaviors and exchange patterns" (p. 51). Macneil (1980) suggests that one of the primal roots of contracts is society and distinguishes between discreet and relational exchange. Drawing upon Macneil's (1980) social contract theory, Heide and John (1992) presents measures for three important norm types governing long-term relationships in marketing channels: solidarity, flexibility and information exchange. These norms are equally relevant for the context of this study.

\subsection{Relationship Quality}

Relationship quality typically manifests in several distinct, although related constructs (Dwyer \& Oh, 1987; Rousseau, 1995; Kumar et al., 1995). Although there is no one agreed upon final prescription for developing long-term buyer-seller relationships, trust and effort are believed to be central issues. Dwyer et al. (1987) underlines the importance of trust, commitment and disengagement. Kumar et al. (1995) add conflict and two constructs that are at the opposite side of the disengagement: willingness to invest and expectations of continuity. Jap, Manolis, and Weitz (1999) suggest that these constructs manifest at varying levels for different levels of relationship quality in a relationship. This study draws upon past research in channel literature to introduce relationship quality as having multiple dimensions: trust, conflict, expectation of continuity and willingness to invest.

\subsection{Fairness in Channel Relationships}

A reseller's perception of supplier fairness is expected to enhance reseller relationship quality (Kumar et al., 1995). Fairness constituents are suggested to be necessary to nurture and protect the trust between the channel partners (Dwyer et al., 1987; Morgan \& Hunt, 1994). Also, firms with a positive reputation of fairness create more trust and expectation of continuity at their exchange partners (Anderson \& Weitz, 1989). Griffith et al., (2005) explores the effects of both procedural and distributive justice on long-term orientation and relational behavior. Their findings indicate that the perceived procedural and distributive fairness of a supplier's policies enhance the long-term orientation and relational behaviors of its distributor, which are also associated with decreased conflict. Weitz and Jap (1995), in their proposition of a framework for channel relationship management, refer to firm's reputation and history of fairness and consideration as antecedent of healthy relationships. Robicheaux and Coleman (1994) uses political economy frame to explain performance and demonstrates how fairness incumbents such as role integrity, tolerance for control, communication, cooperation help explain firm's polity performance which includes relationship quality and commitment. Dyer and Singh (1998) study the determinants of interorganizational competitive advantage and they propose fairness related concepts such as transparency, discouraging free-riding, employing self-enforcement, knowledge-sharing routines as determinants of relational rents. Ring and Van de Ven 
(1994) draws attention to the importance of fair informal processes in order to develop cooperative interorganizational relationships, and praise trusting social relationships between willful and conflicting individuals to generate problem solving genes. In sum, along with explicit lines of research for fairness; research in marketing channels concerning performance and competitively advantageous relationships employs diverse conceptualizations of traits of fairness. This study utilizes the prominent conceptualization of fairness in marketing channels with two components: distributive fairness and procedural fairness. Distributive fairness refers to the reseller's perception of earnings and other outcomes that it receives from its relationship with the supplier (Kumar et al., 1995). Following these research lines, this study conceptualizes distributive fairness as a firm's comparison of its actual outcomes to those outcomes the firm believes it deserves. Procedural fairness refers to the reseller's perception of supplier's fairness in its policies and processes in relation to its resellers. Procedural fairness has either been conceptualized globally or as a set of components. This study adapts the componential approach implemented by Kumar et al. (1995) as its components were pertinent at practical level with the piloted resellers.

\subsection{Fairness Model}

Researchers studied to provide a framework for developing long-term buyer-seller relationships (Dwyer et al., 1987). Relational view put fairness and relational behaviors forward as sources of interorganizational competitive advantage (Dyer \& Singh, 1998). In channels research, Morgan and Hunt (1994) placed trust and commitment as central elements to business relationships and declared them as essential for understanding channel performance as key mediators. Trust related variables like commitment, conflict, long-term orientation was examined in various literatures: trust increases commitment, enhances long-term orientation and helps create an environment for positive conflict where less powerful dares to contest its conflicting ideas. Again, research has been conducted to identify trust's and related variables' effects on relational behaviors of channel members (Borch, 1994; Ganesan, 1994; Kumar et al., 1995; Geyskens et al., 1996; Yilmaz, Sezen, \& Özdemir, 2005). All these congruent efforts to understand the "soft side" are activated by the acceptance that they lead to efficiencies and effectiveness in business relationships; these efficiencies in return help deliver "hard results" such as successful field execution and improved financial performance. Encompassing trust and its important related variables in channels, Kumar et al. (1995) proposed a multi-dimensional construct for understanding channels: relationship quality. Relationship quality comprises of trust and variables that are related to trust. It is very instrumental for the purpose of this research which suggests that relationship quality is a strong mediator and is a continuous source to extract relational behaviors that would otherwise be interrupted. The field teaches us that, even in the presence of some daily fairness problems which would lead an exchange member to question fairness of the other, relationships 
with good quality will hold to provide expected behaviors for some interval of time. Field observations suggest that fairness is important to provoke relational behaviors and relationship quality acts like a secondary or emergency type of power source to keep relational behaviors coming and "alive for shortages of fair treatments". In contrary perceived unfairness is damaging to contractual relationships in distribution channels; it brings out the opportunistic behavior and increases conflict among the channel members (Samaha, Palmatier, \& Dant, 2011), whereas low concern for fairness helps achieve greater profits for the entire supply chain by favoring revenue-sharing contracts among other types (Xiao, Chen, Xie, \& Wang, 2020). The standard profit seeking economical model is questioned for the absence of considerations for fairness and the positive role of fair treatment on desired actions of customers, tenants and employees are underlined (Kahneman, Knetsch, \& Thaler, 1986). Ring and Van de Ven (1994) suggest an encompassing framework to understand how cooperative relationships develop between the firms. This framework provides a good analogy for this research's context: it includes an everyday dimension, that is comprised of negotiations, formal bargaining and informal sense making through which interpretations are formed based on expectations from and trust to the exchange partner. The framework argues that these daily negotiations feed the commitments for future actions through the interplay of formal legal and psychological contracts. Then there is execution or actions, that are affected by the commitments and in a circular way affects the new negotiations. So keeps the cycle turning to create or destroy the cooperative relationships. At the heart of the cycle, there is equity and efficiency.

Marrying field observations with the extensively studied variables in channels and behaviors literatures, this study proposes a fairness model. Following the footprints of cited research lines, the model of this study suggests that fairness issues in everyday dealings shape the relationship quality between the partners and also have direct and indirect effects on relational behaviors. There is strategic advantage to be harnessed through channel relationship management. Weitz and Jap (1995) lays this point out as "Manufacturers, distributors, and retailers have recognized that the management of channel distribution activities offers significant opportunities for firms to create strategic advantage and achieve extraordinary financial performance" (p. 308). In this study, an important segment of our national trade, a marketing channel network consisting of the marketing firm and independent retailers is examined. The purpose of the study is to understand the relationships between fairness, relationship quality and relational behaviors for the channel network mentioned above.

\section{Methodology}

The data was gathered from face to face interviews with four hundred Tekel Shops. Istanbul was chosen for data collection with its various neighborhoods of cultural and economic variety. Due to representativeness of Istanbul in its enti- 
rety, other regions were avoided for interpretation purposes. After the scales were adapted from global literature for fairness, relationship quality and relational behaviors, in-depth interviews were performed with ten pilot retailers to clarify issues regarding the items. After running another twenty pilots with the field research companies to finalize the questionnaire, four hundred surveys were completed.

Structural equation modeling was used to examine the relationship between fairness and relational behaviors and the mediational effects of relationship quality. Structural equation modeling, a method based on factor analysis, is widely used in recent research in the areas of psychology, sociology and management. In the literature, the theories that underline cause and effect relationships were initially examined by regression analysis. Later, path analysis, confirmatory factor analysis and finally structural equation modeling which combines regression techniques, factor analysis and path analysis had followed. Structural equation modeling works through two types of models that work in coordination: a measurement model that confirms relationships between the observed and latent variables, and a structural model that explores the cause and effect relationships between the exogenous and endogenous latent variables. In line with requirements of structural equation modeling, first measurement models for scales were developed and analyzed for the model fit and validity. Then, the structural model was developed and analyzed for the model fit and cause and effect relationships.

\subsection{Sample and Data Collection}

The universe for the research sample is comprised of Tekel Shops which held a legal license to sell alcoholic beverages and tobacco. In order to participate in retail or distribution business for tobacco or alcoholic beverages, the business entities need to have an appropriate license from the government bodies. As of December 2019, the number of retailers with active retail license for alcoholic beverages and tobacco are respectively 50.402 and 178.389 in Turkey; these numbers are 7.592 and 25.770 in Istanbul. Sample size was defined as four hundred to satisfy the rule that the sample size should be greater than 5 times the number of items (Hatcher, 1994). The number of participants from each district was taken proportionately to the number of alcoholic beverages license held in that district. The final determination of the participants was actualized by random selection from the same list. To capture and benefit from the variability that might exist amongst the FMCG firms, four main product categories were chosen to be surveyed: soft drinks, beer, alcoholic beverages and tobacco. They were given quotas of hundred each. Key informant methodology was used to identify the recipients for the questionnaires (Kumar, Stern, \& Anderson, 1993). After being assigned randomly to a category, the participants were first probed if they were the main responsible of the shop and if the answer was positive than they were asked to answer the questions by referring to their major supplier in the chosen catego- 
ry. In total, five hundred ten retailers were visited in a period of two months, about hundred ten observations were deleted due to strict control reasons.

\subsection{Scales}

Scales were adopted from channel marketing literature. In line with the behavioral research in channels (Heide \& John, 1992; Lusch \& Brown, 1996), three of Macneil's relational norms; flexibility, solidarity and information sharing were adapted for our context from the relational behaviors scale that was used by Griffith et al., (2005). Fairness and relationship quality scales were adopted from Kumar et al. (1995). Several original items were added to scales based on the insights gathered from in-depth interviews. All scales are 7-point Likert type. Seven in-depth interviews were held with retailers to check the interpretation of the items and to search for additional insights. Five in-depth interviews were additionally held with marketing companies' salespeople to develop an understanding of the relevancy of concepts from their perspectives to increase content validity. Ten questionnaires were mailed to distributor owners and answered, thereafter phone interviews were held with them to clarify any issues of understanding to reassure the sensibility of the items and to improve content validity. The abbreviation "i.e." means "that is", and the abbreviation "e.g." means "for example".

\subsection{Limitations of the Study}

The sample chosen for the research are Tekel Shops that are situated in Istanbul. Therefore, there might be regional limitations to extend the results of this study. However, minimization of unobserved heterogeneity effect from different regions will strengthen the causal interferences and help the interpretation of results. Also, Istanbul's large number of heterogenous districts provide a vast variety of socio-economical mosaic that exists in Turkey which increases representability of the study.

\section{Research Model}

In this work, the concepts of fairness, relational behaviors and relationship quality were studied in marketing channels context consisting of companies from alcoholic and non-alcoholic beverages and tobacco sectors, their exclusive distributors and Tekel Shop retailers. Tekel Shops are convenience shops with larger share of their sales and profit coming from tobacco and alcoholic beverage products. The mediational effects of relationship quality for fairness on relational behaviors were examined. The model has fairness factors as the independent variables and relational behavior as the dependent variable. Relationship quality is used as a mediating variable in the model.

\section{Hypotheses Development}

Tekel Shops, a large number of locally owned independent shops are an important part of the social texture of the neighborhood and Turkish channel market 
segmentation. It is a unique and dynamic segment for Turkish individuals with entrepreneurship appetite, a big heart and mostly limited capital. They provide a public service in a somehow contradictory segment of FMCG that is highly regulated and stressful. Management practice in this segment demands a higher degree of solidarity, flexibility and information sharing amongst the channel members, or in other words the provision of relational behaviors. Hence understanding relational behaviors and their antecedents is of great importance. Suppliers must precisely comprehend the consequences of their management style on the behavior of this special set of small business owners to tap on their relational behaviors. Therefore, fairness and its effects on relationship quality and relational behaviors assume great value for this context.

In line with the literature on relational behaviors (Morgan \& Hunt, 1994; Kumar et al., 1995; Yilmaz et al., 2005), fairness would be hypothesized to have a positive effect on retailer's relational behavior for the context. In line with the trust related research (Geyskens, Steenkamp, Scheer, \& Kumar, 1996; Zaheer, McEvily, \& Perrone, 1998; Barney \& Hansen, 1995), and also based on field observations; relationship quality, which has trust and trust related variables at its core, would be hypothesized to have a direct effect on relational behavior. Relationship quality is also hypothesized to have a mediating effect on relational behavior for procedural and distributive fairness. Hypotheses for the research are:

H1: Procedural fairness will have a significant positive effect on relationship quality and retailer's relational behavior towards the firm;

H2: Distributive fairness will have a significant positive effect on relationship quality and retailer's relational behavior towards the firm;

H3: Relationship quality will have a significant positive effect on retailer's relational behavior towards the firm;

H4: Relationship quality will have a significant mediating effect between procedural and distributive fairness of the firm and retailer's relational behavior towards the firm.

\section{Findings}

Data collected by questionnaires was initially examined for descriptive statistics, frequency distributions, reliability and validity analyses. Cronbach Alpha reliability test was used to test the reliability of the scales in the study. Scales were subjected to exploratory factor analyses to determine validity. Finally, in line with the aim of the research, AMOS program was used to examine the complex relationships between the variables by SEM analysis for measurement and structural models. IBM SPSS version 25 and AMOS version 24 were used for analyses in the study. Findings about the analyses and interpretation of these findings are presented hereafter in this chapter.

\subsection{Structural Equation Model of the Study}

The structural equation model is constructed in line with the findings of the first 
and second levels of measurement models. In this part of the study, the relationships between all latent and observed variables of the study are defined and modeled according to the purpose of the research. The model for the firm data can be seen in Figure 1. The effect of procedural fairness on relationship quality is 0.713 , important in absolute standardized value and significant at $p=0.001$. The effect of distributive fairness on the relationship quality is 0.14 ; significant at $p=0.001$. The effect of procedural fairness on relational behavior is 0.38 and significant at $p=0.001$. The standardized effect of distributive fairness on relational behavior is 0.14 and significant at $p=0.063$. The effect of relationship quality on relational behavior is 0.584 and significant at $p=0.001$. The effects of procedural fairness latent variable on its lower dimensions CONACT and IMPCO are 1.02 and 0.582 ; these figures are 0.47 for affective conflict, 0.66 for expectation of continuity and 1.06 for the relationship quality; finally, for the

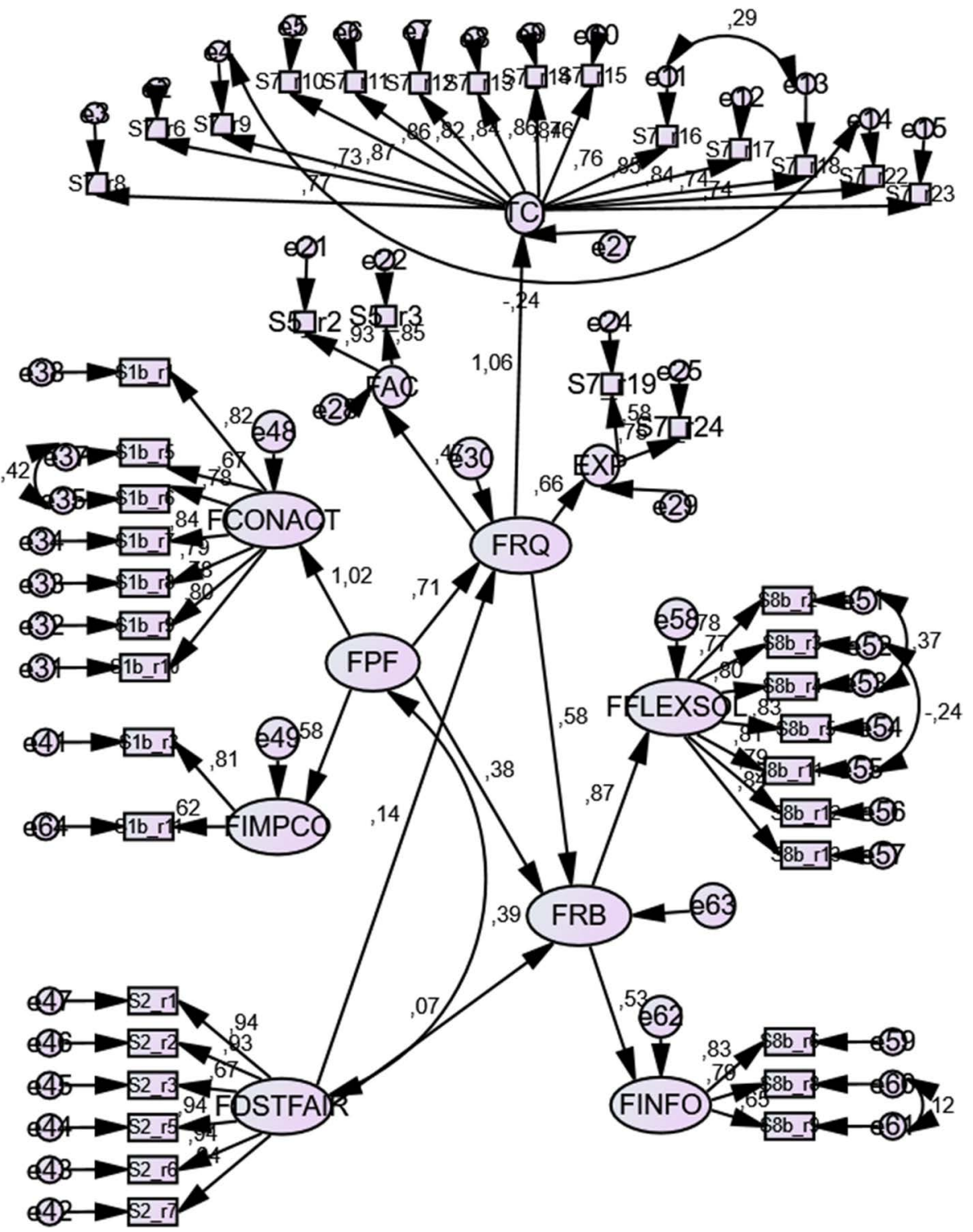

Figure 1. Structural equation model firm (FMV7). 
relational behavior they are 0.582 for INFO and 0.87 for FLEXSOL. These values also expressed as regression coefficients are all statistically significant at $p=$ 0.001 level.

To determine how well the structural equation model fits the data collected from the retailers for the firm, model fit indices are calculated and shown in $\mathrm{Ta}$ ble 1 . As these values are examined as a whole and compared to threshold values, all are acceptable or excellent levels and the model can be said to have an acceptable fit.

\subsection{Mediating Effect of Relationship Quality}

In the final step, the mediating effect of the relationship quality on relational behavior is examined. The findings of the mediation analysis for the firm data are shown in Table 2 . The relationship quality has a partial mediating effect of 0.416 for the procedural fairness at $p<0.050$ level of confidence and its total effect is large in size (0.80) and significant at $p<0.01$ level of confidence. The relationship quality has a partial mediation role for the procedural fairness of the firm on relational behaviors. The distributive fairness has an indirect effect of 0.083 significant at $p<0.100$ level of confidence, and the total effect 0.143 has an

Table 1. Model fit measures-structural equation model firm.

\begin{tabular}{cccc}
\hline & \multicolumn{2}{c}{ Table Column Head } & \\
\hline Measure & Estimate & Threshold & Interpretation \\
\hline CMIN & 2306.051 & -- & -- \\
DF & 841 & -- & -- \\
CMIN/DF & 2.742 & Between 1 and 3 & Excellent \\
CFI & 0.904 & $>0.95$ & Acceptable \\
SRMR & 0.079 & $<0.08$ & Excellent \\
RMSEA & 0.066 & $<0.06$ & Acceptable \\
PClose & 0 & $>0.05$ & Not Estimated \\
\hline
\end{tabular}

Table 2. Mediating effects—structural equation model firm.

\begin{tabular}{|c|c|c|c|c|}
\hline \multicolumn{5}{|c|}{ Table Column Head } \\
\hline Hypotheses & $\begin{array}{l}\text { Standardized } \\
\text { Direct Effect }\end{array}$ & $\begin{array}{l}\text { Standardized } \\
\text { Indirect Effect }\end{array}$ & $\begin{array}{l}\text { Standardized } \\
\text { Total Effect }\end{array}$ & $\begin{array}{c}\text { Mediating } \\
\text { Effect }\end{array}$ \\
\hline $\mathrm{FPF}>\mathrm{FRQ}$ & $0.713^{\star *}$ & - & $0.713^{\star *}$ & - \\
\hline $\mathrm{FDF}>\mathrm{FRQ}$ & $0.143^{*}$ & - & $0.143^{*}$ & - \\
\hline $\mathrm{FPF}>\mathrm{FRB}$ & $0.383^{*}$ & $0.416^{*}$ & $0.80^{\star *}$ & - \\
\hline $\mathrm{FDF}>\mathrm{FRB}$ & 0.074 & $0.083^{\dagger}$ & $0.157^{\star}$ & - \\
\hline $\mathrm{FRQ}>\mathrm{FRB}$ & $0.584^{\star}$ & - & $0.584^{\star}$ & - \\
\hline $\mathrm{FPF}>\mathrm{FRQ}>\mathrm{FRB}$ & - & $0.416^{\star}$ & - & Partial \\
\hline $\mathrm{FDF}>\mathrm{FRQ}>\mathrm{FRB}$ & - & $0.083^{\dagger}$ & - & Full \\
\hline
\end{tabular}

Significance of correlations: ${ }^{\dagger} p<0.100,{ }^{*} p<0.050,{ }^{* *} p<0.010,{ }^{* * *} p<0.001$. 
acceptable confidence level, at $p<0.10$. The relationship quality has a full mediating role for the distributive fairness of the firm on relational behavior.

\section{Conclusion}

A "fairness" tale on how to grow business together...

In marketing channels where long-term relationship is a characterizing aspect, relational behaviors are important variables of interest and subject to intensive research. Adapted by channel researchers out of Macneil's original relational norms; flexibility, solidarity and information sharing are three relational behaviors that interest marketing channels most as they have a conclusive saying in the success or failure of most marketing initiatives. What are the most important factors that drive relational behaviors from the channel partners? Which one has the greatest impact on them? Fairness of the channel partner; or, trust, commitment, affect, long-term orientation towards the channel partner? Is distributive fairness, the factor that occupies most of the verbal exchange between partners, more important than the procedural fairness? Is fairness more important than relationship quality? Does relationship quality have an effect on relational behaviors? What happens when there is a shortage of fair practices? Is it worth investing in relationship quality for those times of trouble: unfair treatments? These questions were at the roots of this research where the relationship between fairness and relational behaviors and the mediating role of relationship quality were studied. The research was conducted with data that were gathered from four hundred Turkish convenience tobacco and liquor shops or shortly Tekel Shops with their local name. The study encompasses the testing of 1) the effects of the fairness and 2) relationship quality on relational behaviors, and 3) the mediation role of relationship quality on relational behaviors for fairness.

The significant effect of procedural fairness on relationship quality (0.713) is in line with channel marketing literature (Kumar et al., 1995). The effect of distributive fairness is also significant on relationship quality; however, the size of the effect is much smaller (0.143). Indirect effect of procedural fairness on relational behavior is 0.416 . Procedural fairness of the firm has a significant direct effect (0.383) on relational behavior even in the presence of relationship quality as a mediating variable. Furthermore, the size of its total effect on relational behavior is increased (0.800) by partial mediation of relationship quality. On the side of the distributive fairness, the indirect effect of distributive fairness on relational behavior is $0.083^{\dagger}$ for the firm. The direct effect for distributive fairness of the firm on relational behavior is also not significant (0.074). However, the size of its total effect on relational behavior is increased to significance $(0.157)$ by full mediation of relationship quality. The literature on the mediating effect of relationship quality for fairness on relational behavior is rather limited. However, similar mediation findings for lower dimensions of the relationship quality such as trust, commitment and long-term orientation do exist for different contexts (Andaleeb, 1995; Geyskens et al., 1996). 
The results of the study underline the relative importance of procedural fairness (PF) over distributive fairness (DSTFAIR) to build relationship quality. Also, relationship quality $(\mathrm{RQ})$ has a significant and large size effect on $\mathrm{RB}$ relational behavior (RB) for the data. PF has a direct significant effect on relational behavior. This confirms the importance of the firm's role in the channel for providing procedural fairness as the model does not necessitate the mediation of RQ to obtain $\mathrm{RB}$ for the firm data. This direct effect is understandable as the firm has everything to do about financial policies that have direct effect on overall economic gains of the channel members. Additionally, RQ partially mediates the effect of PF on RB and as a result PF has a total effect of 0.80 on $\mathrm{RB}$, greatest total effect for the model. RQ also fully mediates the effect of DSTFAIR on RB. That mediation effect underlines the importance of the relationship quality in order to leverage financial reward system for relational behaviors. In sum, theoretical model reveals six important relationships. First, procedural fairness has a significant effect on relationship quality. Second, distributive fairness has a significant effect on relationship quality. Third, procedural fairness has approximately five times more leverage on relationship quality compared to distributive fairness. Fourth, procedural fairness of the firm has a direct effect on relational behavior. Fifth, relationship quality has a significant and large effect on relational behavior. Sixth, relationship quality mediates procedural and distributive fairness' effects on relational behavior.

There is an important and very positive message in the ratio of the effects of procedural fairness versus distributive fairness. It tells marketing firms that it is well worth investing in procedural fairness or in practical terms management of relationships. It shows that even if distributive fairness is somehow not perceived high, the game is not over. Actually, a sustainable course is to put forward elements of fair management by boundary personnel, because fair management of relationships or being procedurally fair is an internal resource of the company that can be tracked, measured and developed. Distributive fairness issues generally dominate most of the communication and are feared to be disengaging in relationships. However, the results of this study show that the leverage of procedural fairness on relationship quality is around five times compared to distributive fairness. This is encouraging news as it points out to a fertile and more manageable area to develop better relationships. Second finding of the study is the effect of relationship quality on relational behavior (0.584). Relationship quality is the variable which has the greatest direct effect on relational behavior. This finding establishes relationship quality as an antecedent for relational behavior. This result is backed by the literature (Jap et al., 1999). Retailers that experience higher relationship quality with their channel partners will provide higher relational behavior in return. Retailers that trust and that are committed to their channel partners with a positive affect and an expectation of continuity are more flexible in their dealings and provide more solidarity and information to their suppliers. Finally, full mediation of relationship quality brings out the indirect 
effect of distributive fairness on relational behaviors. Otherwise distributive fairness of the firm has no significant direct effect on relational behavior of the retailer. The study shows that distributive fairness is only effective on relational behaviors when mediated by relationship quality. In that respect, this research contributes to channel marketing literature and to managerial practice in FMCG sector, specifically in regulated channels.

Based on the results of the research, human resources may consider including fairness dimensions in its evaluation and development procedures. Evaluating boundary personnel's customer perception for firm fairness dimensions would add value to the organization as they each point individually to an area of personal improvement. This would lead to a plan for the improvement of the skill itself or its perception. Furthermore, the effect size of procedural fairness on relationship quality for the data suggests an opportunity for the suppliers to look ahead of the usual grind of everyday conflicts over profits with customers. Shared profits are somehow limited by external factors and governed by the invisible hand of the market, however its effect on the relationship quality and on relational behaviors is also low compared to the effect of procedural fairness. Therefore, suppliers that pay attention to implementation of procedural fairness dimensions, would benefit in greater increments from increased relationship quality and in return increased relational behavior from their customers. For example, refutability and explanation are rather two very sought after but less offered dimensions of the fairness based on the research data. The incremental adoption of these dimensions by suppliers to govern relationships, would not only benefit the trade segment, but a larger section of the society due to former's vast stretch over socio-economical map. In fact, this line of research led to improvements on trade laws in many developed countries.

As mediating effect of relationship quality $(0.416)$ between procedural fairness and relational behavior is evaluated, retailer's perception to have a higher degree of relationship quality with their suppliers has an increasing effect on their relational behaviors. In that respect, boundary personnel who provide procedural fairness in their dealings with the customers would facilitate their relational behaviors. Two-way communication, refutability of supplier's decisions, explanation of new undertakings that effect the retailers, knowledge ability about retailer's working conditions, impartiality in carrying out daily operations and finally courtesy will add to relationship quality score. All of these management style preferences will therefore contribute to retailers increased relational behavior.

When evaluating the importance of relational behavior to marketing channels, one may think of the example of well-oiled engine. In a well-oiled engine, the parts move effortlessly, turning energy into action efficiently. If the energy for a smooth action in the business machine is the fairness, relationship quality is the oil and the action is relational behavior. As the result of an effective machine is the resource efficiency, same can be said for the channels. With trust and commitment at its heart, relationship quality would diminish the cost of over control 
and destructive conflicts. Hence, the relational behaviors will prevail in line with studies that show the effects of trust, commitment, and other relationship quality dimensions' individual effects on the performance (Morgan \& Hunt, 1994; Kumar et al., 1995).

An important responsibility lays in the hands of suppliers' leadership as to adapt fair management dimensions to everyday practice. This fairness movement has to begin with internalization of the fairness values and communication of their immediate benefits. The follow up of healthy implementation of these values should be part of human resources evaluation procedures. The evaluation of boundary personnel should not be assumed complete without the customer perception score concerning fair management principles. A trade segment that perceives itself valued and participative is a great value not only for the channel members but also for the whole society with its overreaching social ramifications.

\section{Conflicts of Interest}

The author declares no conflicts of interest regarding the publication of this paper.

\section{References}

Achrol, R. S., \& Kotler, P. (1999). Marketing in Network Economy. Journal of Marketing, 63, 146-163. https://doi.org/10.1177/00222429990634s114

Andaleeb, S. S. (1995). Dependence Relations and Moderating Role of Trust: Implications for Behavioral Intentions in Marketing Channels. International Journal of Research in Marketing, 12, 157-172. https://doi.org/10.1016/0167-8116(94)00020-O

Anderson, E., \& Weitz, B. (1989). Determinants of Continuity in Conventional Industrial Channel Dyads. Marketing Science, 8, 310-323. https://doi.org/10.1287/mksc.8.4.310

Antia, K. D., \& Frazier, G. L. (2001). The Severity of Contract Enforcement in Interfirm Channel Relationships. Journal of Marketing, 65, 67-81.

https://doi.org/10.1509/jmkg.65.4.67.18385

Barney, J. B., \& Hansen, M. H. (1995). Trustworthiness as a Source of Competitive Advantage. Strategic Management Journal, 15, 175-190.

https://doi.org/10.1002/smj.4250150912

Borch, O. J. (1994). The Process of Relational Contracting: Developing Trust-Based Strategic Alliances among Small Business Enterprises. Advances in Strategic Management Journal, 10B, 113-135.

Cohen-Charash, Y., \& Spector, P. E. (2001). The Role of Justice in Organizations: A Meta-Analysis. Organizational Behavior and Human Decision Processes, 86, 278-231. https://doi.org/10.1006/obhd.2001.2958

Dwyer, R. F., \& Oh, S. (1987). Output Sector Munificence Effects on the Internal Political Economy of Marketing Channels. Journal of Marketing Research, 24, 347-358. https://doi.org/10.1177/002224378702400402

Dwyer, R. F., Schurr, P. H., \& Oh, S. (1987). Developing Buyer-Seller Relationships. Journal of Marketing, 51, 11-27. https://doi.org/10.1177/002224298705100202

Dyer, J. H., \& Singh, H. (1998). The Relational View: Cooperative Strategy and Sources of Interorganizational Competitive Advantage. The Academy of Management Review, 23, 660-679. https://doi.org/10.5465/amr.1998.1255632 
Dyer, J. H., Singh, H., \& Kale, P. (2008). Splitting the Pie: Rent Distribution in Alliances and Networks. Managerial and Decision Economics, 29, 137-148. https://doi.org/10.1002/mde.1391

Frazier, G. L., \& Summers, J. O. (1984). Interfirm Influence Strategies and Their Application within Distribution Channels. Journal of Marketing, 48, 43-55. https://doi.org/10.1177/002224298404800305

Ganesan, S. (1994). Determinants of Long-Term Orientation in Buyer-Seller Relationships. Journal of Marketing, 58, 1-19. https://doi.org/10.1177/002224299405800201

Gaski, J. F. (1984). The Theory of Power and Conflict in Channels of Distribution. Journal of Marketing, 48, 9-29. https://doi.org/10.1177/002224298404800303

Geyskens, I., Steenkamp, J. B. E. M., \& Kumar, N. (1998). Generalizations about Trust in Marketing Channel Relationships Using Meta-Analysis. Journal of Research in Marketing, 15, 223-248. https://doi.org/10.1016/S0167-8116(98)00002-0

Geyskens, I., Steenkamp, J. B. E. M., \& Kumar, N. (2006). Make, Buy, Or Ally: A Transaction Cost Theory Meta-Analysis. Academy of Management Journal, 49, 519-543. https://doi.org/10.5465/amj.2006.21794670

Geyskens, I., Steenkamp, J. B. E. M., Scheer, L. K., \& Kumar, N. (1996). The Effects of Trust and Interdependence on Relationship Commitment. International Journal of Research in Marketing, 13, 303-317. https://doi.org/10.1016/S0167-8116(96)00006-7

Griffith, D. A., Harvey, M. G., \& Lusch, R. F. (2005). Social Exchange in Supply Chain Relationships: The Resulting Benefits of Procedural and Distributive Justice. Journal of Operations Management, 24, 85-98. https://doi.org/10.1016/j.jom.2005.03.003

Hatcher, L. (1994). A Step-by-Step Approach to Using the SAS System for Factor Analysis and Structural Equation Modeling. Cary: SAS Institute, Inc.

Heide, J. B., \& John, G. (1992). Do Norms Matter in Marketing Relationships. Journal of Marketing, 56, 32-44. https://doi.org/10.1177/002224299205600203

Heide, J. B., Wathne, K. H., \& Rokkan, A. I. (2007). Interfirm Monitoring, Social Contracts, and Relationship Outcomes. Journal of Marketing Research, 44, 425-433. https://doi.org/10.1509/jmkr.44.3.425

Homan, G. C. (1958). Social Behavior as Exchange. American Journal of Sociology, 63, 597-606. https://doi.org/10.1086/222355

Hopkinson, G. H., \& Blois, K. J. (2014). Power-Based Research in Marketing Channels: A Narrative Review. International Journal of Management Reviews, 16, 131-149. https://doi.org/10.1111/ijmr.12013

Hunt, S. D. (2015). The Bases of Power Approach to Channel Relationships: Has Marketing's Scholarship Been Misguided? Journal of Marketing Management, 31, 747-764. https://doi.org/10.1080/0267257X.2014.987988

Hunt, S. D., \& Nevin, J. R. (1974). Power in a Channel of Distribution: Sources and Consequences. Journal of Marketing Research, 11, 186-193. https://doi.org/10.1177/002224377401100210

Ivens, B. S., \& Blois, K. J. (2004). Relational Exchange Norms in Marketing: A Critical Review of MacNeil's Contribution. Marketing Theory, 4, 239-263. https://doi.org/10.1177/1470593104045603

Jap, S. D., Manolis, C., \& Weitz, B. A. (1999). Relationship Quality and Buyer-Seller Interactions in Channels of Distribution. Journal of Business Research, 46, 303-313. https://doi.org/10.1016/S0148-2963(98)00032-0

Kahneman, D., Knetsch, J. L., \& Thaler, R. H. (1986). Fairness and the Assumptions of Economics. Journal of Business, 59, 285-300. https://doi.org/10.1086/296367 
Kumar, N., Scheer, L. K., \& Steenkamp, J. B. E. M. (1995). Effects of Supplier Fairness on Vulnerable Resellers. Journal of Marketing Research, 32, 54-65. https://doi.org/10.1177/002224379503200107

Kumar, N., Stern, L. W., \& Anderson, J. C. (1993). Conducting Interorganizational Research Using Key Informants. The Academy of Management Journal, 36, 1633-1651. https://doi.org/10.2307/256824

Lusch, F. L. (1976). Sources of Power: Their Impact on Intrachannel Conflict. Journal of marketing Research, 13, 382-390. https://doi.org/10.1177/002224377601300408

Lusch, R. F., \& Brown, J. R. (1996). Interdependency, Contracting, and, Relational Behavior in Marketing Channels. Journal of Marketing, 60, 19-38. https://doi.org/10.1177/002224299606000404

Macneil, I. R. (1980). The New Social Contract. New Haven, CT: Yale University Press.

Macneil, I. R. (1985). Relational Contract: What We Do And Do Not Know. Wisconsin Law Review, 4, 483-525.

Morgan, R. M., \& Hunt, S. D. (1994). The Commitment-Trust Theory of Relationship Marketing. Journal of Marketing, 58, 20-38. https://doi.org/10.1177/002224299405800302

Palmatier, R. W., Dant, R. P., \& Grewal, D. (2007). A Comparative Longitudinal Analysis of Theoretical Perspectives of Interorganizational Relationship Performance. Journal of Marketing, 71, 172-194. https://doi.org/10.1509/jmkg.71.4.172

Rauyruen, P., Miller, K. E., \& Barrett, N. J. (2007). Relationship Quality as a Predictor of B2B Customer Loyalty. Journal of Business Research, 60, 21-31. https://doi.org/10.1016/j.jbusres.2005.11.006

Raven, B. H. (2008). The Bases of Power and the Power/Interaction Model of Interpersonal Influence. Analyses of Social Issues and Public Policy, 8, 1-22. https://doi.org/10.1111/j.1530-2415.2008.00159.x

Reve, T., \& Stern, L. W. (1979). Interorganizational Relations in Marketing Channels. Academy of Management Review, 4, 405-416. https://doi.org/10.5465/amr.1979.4289111

Ring, P. S., \& Van de Ven, A. H. (1994). Developmental Processes of Cooperative Interorganizational Relationships. Academy of Management Review, 19, 90-118. https://doi.org/10.5465/amr.1994.9410122009

Ritter, T., \& Gemünden, H. G. (2003). Network Competence: Its Impact on Innovation Success and Its Antecedents. Journal of Business Research, 56, 745-755. https://doi.org/10.1016/S0148-2963(01)00259-4

Robicheaux, R. A., \& Coleman, J. E. (1994). The Structure of Marketing Channel Relationships. Journal of the Academy of Marketing Science, 22, 38-51. https://doi.org/10.1177/0092070394221004

Rosenberg, L. J., \& Stern, L. W. (1970). Toward the Analysis of Conflict in Distribution Channels: A Descriptive Model. Journal of Marketing, 34, 40-46. https://doi.org/10.1177/002224297003400407

Rousseau, D. M. (1995). Promises in Action: Psychological Contracts in Organizations. Newbury Park, SA: Sage Publications.

Samaha, S. A., Palmatier, R. W, \& Dant R. P. (2011). Poisining Relationships: Perceived Unfairness in Channels of Distribution. Journal of Marketing, 75, 99-117. https://doi.org/10.1509/jmkg.75.3.99

Skinner, S. J., Gassenheimer, J. B., \& Kelley, S. W. (1992). Cooperation in Supplier-Dealer Relations. Journal of Retailing, 68, 174-193.

Thorelli, H. B. (1986). Networks: Between Markets and Hierarchies. Strategic Manage- 
ment Journal, 7, 37-51. https://doi.org/10.1002/smj.4250070105

Weitz, B. A., \& Jap, S. D. (1995). Relationship Marketing and Distribution Channels. Journal of the Academy of Marketing Science, 23, 305-320. https://doi.org/10.1177/009207039502300411

Wilkinson, I. F. (1979). Power and Satisfaction in Channels of Distribution. Journal of Retailing, 55, 79-94.

Xiao, Q., Chen, L., Xie, M., \& Wang, C. (2020). Optimal Contract Design in Sustainable Supply Chain: Interactive Impacts of Fairness Concern and Overconfidence. Journal of the Operational Research Society. https://doi.org/10.1080/01605682.2020.1727784

Yilmaz, C., Sezen, B., \& Özdemir, O. (2005). Joint and Interactive Effects of Trust and (Inter) Dependence on Relational Behaviors in Long-Term Channel Dyads. Industrial Marketing Management, 34, 235-248.

https://doi.org/10.1016/j.indmarman.2004.07.005

Young, L. C., \& Wilkinson, I. F. (1989). The Role of Trust and Cooperation in Marketing Channels: A Preliminary Study. European Journal of Marketing, 23, 109-122.

https://doi.org/10.1108/EUM0000000000550

Zaheer, A., McEvily, B., \& Perrone, V. (1998). Does Trust Matter? Exploring the Effects of Interorganizational and Interpersonal Trust on Performance. Organization Science, 9, 141-159. https://doi.org/10.1287/orsc.9.2.141 